\title{
AN EFFICIENT ALGORITHM FOR THE DESIGN OF DECENTRALIZED OUTPUT FEEDBACK POWER SYSTEM STABILIZER
}

Chern-Lin Chen, Student Member

Department of Electrical Engineering

National Taiwan University

Taipei, Taiwan
Yuan-Yih Hsu, Member

\section{ABSTRACT}

A new algorithm for the design of decentralized output feedback stabilizers for large-scale electric power systems is presented in this paper. In the proposed approach, the generators which are most effective for stabilizer applications are first identified by using participation factors. Then an efficient algorithm based on decentralized pole assignment is proposed for the determination of the parameters of the power system stabilizers which, due to the difficulty associated with the communication among the geographically dispersed generating stations in a large power system, are essentially decentralized compensators using local generator outputs as their feedback signals. The proposed method is computationally efficient and can be applied to any large-scale system. The simplicity and effectiveness of the proposed method are demontrated hy an example of stabilizer design for a practical power system.

\section{INTRODUCTION}

With the widespread use of fast-speed, high-gain static excitation systems and long-distance transmission lines, many power systems face the problem of dynamic oscillations [1]-[4]. In the literature, various kinds of power system stabilizers such as lead-lag stabilizer [5] - [7], optimal stabilizer [8], variable structure stabilizer [9], and proportional-integral (PI) stabilizer [10] have been proposed to damp out these undesirable oscillations. In the design of any kind stabilizers for large-scale power systems, the identification of optimum installation location as well as the determination of suitable parameters has to be considered since only rather limited numbers of generators among the vast number of generators in the system are equipped with power system stabilizers in most cases.

In this paper, a novel approach based on participation factors is presented for the identification of optimum site. The method is found to be better than the conventional right eigenvector technique [11] in that it requires less control effort to achieve the same degree of damping. Moreover, in view of the special features of a large scale power system that the generators are geographically disperse and only local output signals such as generator speed or power are available, a novel method is proposed for the design of decentralized power system stabilizers. The method is very concise and simple in its mathematical formulation and is applicable to many large-scale systems. Stabilizer design for a practical power system is given as an example to demonstrate the effectiveness of the proposed method.

\section{PROBLEM FORMULATION}

The state equation of an interconnected power system can be written as follows

87 SM 453-4 A paper recommended and approved by the IEEE Power System Engineering Committee of the IEEE Power Engineering Society for presentation at the IEEE/PES 1987 Summer Meeting, San Francisco, California, July $12-17,1987$. Manuscript submitted October 8, 1986; made available for printing May $15,1987$.

$$
\begin{aligned}
& X(t)=A X(t)+B U(t) \\
& Y(t)=C X(t)
\end{aligned}
$$

where $X(t)$ is the state $n$-vector, $U(t)$ is the control m-vector, $Y(t)$ is output $\mathrm{m}$-vector, and $\mathrm{A}, \mathrm{B}$, and $\mathrm{C}$ are constant system matrices of appropriate dimensions. It has been assumed that $\mathrm{m}$ generators will be equipped with stabilizers in order to damp out $\mathrm{m}$ poorlydamped electromechanical mode oscillations. Taking the Laplace transform of eqns. (1) and (2), we have the state equation in frequency domain

$$
\begin{aligned}
& \mathrm{sX}(\mathrm{s})=\mathrm{AX}(\mathrm{s})+\mathrm{BU}(\mathrm{s}) \\
& \mathrm{Y}(\mathrm{s})=\mathrm{CX}(\mathrm{s})
\end{aligned}
$$

The stabilizer output $U(s)$ can be expressed as

$$
\mathrm{U}(\mathrm{s})=\mathrm{H}(\mathrm{s}) \mathrm{Y}(\mathrm{s})
$$

where the stabilizer matrix $\mathrm{H}(\mathrm{s})$ is a diagonal matrix since decentralized stabilizer is considered. In other words, the matrix $\mathrm{H}(\mathrm{s})$ can be written as

$$
H(s)=\left[\begin{array}{ccc}
h_{1}(s) & & 0 \\
& h_{2}(s) & \\
& \ddots & \\
0 & & h_{m}(s)
\end{array}\right]
$$

where $h_{i}(s), i=1, \ldots, m$, are the transfer functions of the $m$ decentralized stabilizers to be determined.

The first step in the design of these decentralized stabilizers is to identify the $m$ generators which are the most effective locations for stability improvement. Then, the parameters of the $m$ transfer functions of the decentralized stabilizers have to be determined based on the criterion of shifting the $\mathrm{m}$ pairs of poorly-damped electromechanical-mode eigenvalues to more desirable locations. These two facets of the overall design problem will be covered in subsequent sections.

\section{IDENTIFICATION OF OPTIMUM STABILIZER LOCATIONS}

The identification of optimum stabilizer locations using participation factors will be examined in this section. Consider a linear time-invariant system whose state equation is given in eqn.(1). The right eigenvectors $r_{i}, i=1,2, \ldots, n$, which are the conventional indices for the identification of stabilizer locations [11], are defined by the following equation

$$
A r_{i}=\lambda_{i} r_{i} \quad, \quad i=1,2, \ldots, n
$$

where $\lambda_{i}$ 's are the eigenvalues of the system. On the other hand, the left eigenvectors $l_{i}$ are defined as follows

$$
\mathrm{l}_{\mathrm{i}} \mathrm{A}=\lambda_{\mathrm{i}} \mathrm{l}_{\mathrm{i}}, \quad \mathrm{i}=1,2, \ldots, \mathrm{n}
$$

Then, the participation factor $p_{i j}$ (the $j$-th state variable $x_{j}$ in the i-th eigenvalue $\lambda_{\mathfrak{i}}$ ) can be defined as

$$
\mathrm{p}_{\mathrm{ij}}=\mathrm{l}_{\mathrm{ij}} \mathrm{r}_{\mathrm{ij}}
$$


where $l_{i j}$ and $r_{i j}$ are the $j$ th element of $l_{i}$ and $r_{i}$, respectively. It is to be noticed that, while the right eigenvector gives the mode shape by describing the activity of the variables when that particular mode is excited, the left eigenvector gives the mode composition by describing what weighted combination of state variables is needed to construct the mode [14]-[15]. The entries of these two eigenvectors are incommensurable since the state vector consists of different physical variables such as angular velocities, angles, flux, etc. Therefore, the magnitudes of the entries of $r_{i}$ and $l_{i}$ will change as the units in the state variables are changed. On the other hand the participation factor is a dimensionless real number which is invariant with the change on the scale of state variables. The participation factor $p_{\mathrm{ij}}$ can be also interpreted as the sensivity of the eigenvalue $\lambda_{i}$ with respect to the diagonal element $a_{j j}$ of $A$, i.e.,

$$
p_{i j}=\partial \lambda_{i} / \partial a_{j j}
$$

Hence, the participation factor as defined in eqn. (9) is a quantitative measure which can provide better insight into the problem how a particular mode (eigenvalue) is affected by the various state variables in the system. As a matter of fact, Verghese et al. [12]-[13] have worked out a reduced mathematical model for the analyses of power system dynamic stability using this characteristic feature of participation factor. The application of participation factor to the identification of stabilizer location has been exploited by the authors [14]. The superiority of participation factors to right eigenvectors is evidenced in that paper by the smaller stabilizer gains obtained by using participation factors than those by eigenvectors. Thus, more effective site for stabilizer application can be identified by the proposed approach.

\section{DECENTRALIZED POWER SYSTEM STABILIZER DESIGN}

Having identified the proper locations of the stabilizers, the only problem left is to determine the parameters of the $\mathrm{m}$ decentralized stabilizers using modal control theory [15] - [16] Although the method described in this section will be applied in this paper to stabilizer design in power systems only, it is a new and simple approach which is applicable to many large scale systems.

Combining eqns. (3), (4), and (5), we obtain

$$
\begin{aligned}
\mathrm{X}(\mathrm{s}) & =(\mathrm{sI}-\mathrm{A})^{-1} \quad \mathrm{~B} \mathrm{U}(\mathrm{s}) \\
& =(\mathrm{sI}-\mathrm{A})^{-1} \quad \mathrm{~B} \mathrm{H}(\mathrm{s}) \mathrm{Y}(\mathrm{s}) \\
& =(\mathrm{sI}-\mathrm{A})^{-1} \quad \mathrm{~B} \mathrm{H}(\mathrm{s}) \mathrm{C} \mathrm{X}(\mathrm{s}) \\
{[\mathrm{I}-} & \left.(\mathrm{sI}-\mathrm{A})^{-1} \text { B H(s)C }\right] \quad \mathrm{X}(\mathrm{s})=0
\end{aligned}
$$

Let $\lambda$ be a prespecified eigenvalue of the closed-loop system which is usually obtained by shifting one of the poorly-damped mechanicalmode eigenvalues to certain desirable location, then we have

$$
\operatorname{det}\left[\mathrm{I}-(\lambda \mathrm{I}-\mathrm{A})^{-1} \mathrm{~B} \mathrm{H}(\lambda) \mathrm{C}\right]=0
$$

since $X(\lambda)$ is not identically zero. Using the identity

$$
\operatorname{det}[I+Q R]=\operatorname{det}[I+R Q]
$$

where $Q$ and $R$ are matrices, we can reduce eqn. (14) to

$$
\operatorname{det}\left[I-C(\lambda I-A)^{-1} B H(\lambda)\right]=0
$$

Equation (15) can be written in an alternative form

$$
\text { where } \begin{gathered}
\operatorname{det}[I-G(\lambda) H(\lambda)]=0 \\
G(s)=C(s I-A)^{-1} B
\end{gathered}
$$

is the transfer function matrix of the open-loop system. Because $\mathrm{H}(\mathrm{s})$ is diagonal, eqn. (16) reduces to

$$
\begin{aligned}
& \operatorname{det}\left[I_{1}-G_{1}(\lambda) h_{1}(\lambda), I_{2}-G_{2}(\lambda) h_{2}(\lambda), \ldots,\right. \\
& \left.\quad I_{i}-G_{i}(\lambda) h_{i}(\lambda), \ldots, I_{m}-G_{m}(\lambda) h_{m}(\lambda)\right]=0
\end{aligned}
$$

where $I_{i}$ is the ith unit column vector and $G_{j}(\lambda)$ is the ith column of $G(\lambda)$. The only problem left is then to find the desired transfer functions from eqn. (18).

In this paper, an efficient algorithm based on Newton-Raphson method is proposed for the determination of unknown parameter vectors $p_{1}, \ldots, p_{m}$ for the $m$ stabilizers. It should be noted that the vector $p_{i}$ contains all the unknown parameters of ith stabilizer whose transfer function is given by $h_{i}(s)$. Therefore, $h_{i}(s)$ depends on $p_{i}$ only. For the example in this paper, there are two unknown variables for each $\mathrm{p}_{j}$

The procedure for the determination of parameter vectors is as follows.

1. Select $\ell=2 m$ prespecified eigenvalues $\lambda_{j}, j=1, \ldots, \ell$.

2. Set the initial guess $P^{(0)}=\left[p_{1}{ }^{(0)} p_{2}{ }^{(0)} \ldots p_{m}^{(0)}\right]^{T}$.

3. The parameter vector $\mathrm{P}^{(\mathrm{r}+1)}$ for the $(\mathrm{r}+1)$ th iteration is updated according to the following equation

$$
\mathrm{P}^{(\mathrm{r}+1)}=\mathrm{P}^{(\mathrm{r})}+\mathrm{J}^{(\mathrm{r})^{-1}} \Delta \mathrm{D}^{(\mathrm{r})}
$$

where $\mathrm{J}^{(\mathrm{r})}$ and $\Delta \mathrm{D}^{(\mathrm{r})}=\left[\Delta \mathrm{d}_{1}{ }^{(\mathrm{r})}, \Delta \mathrm{d}_{2}{ }^{(\mathrm{r})}, \ldots, \Delta \mathrm{d}_{\mathrm{j}}^{(\mathrm{r})}, \ldots, \Delta \mathrm{d}_{\ell}^{(\mathrm{r})}\right]^{\mathrm{T}}$ are the Jacobian matrix and the determinant mismatch vector for the rth iteration, respectively. They are derived as follows.

From eqn. (18), the elements of the determinant mismatch vector are given by

$$
\begin{aligned}
\Delta d_{j}^{(r)}= & \operatorname{det}\left[I_{1}-G_{1}\left(\lambda_{j}\right) h_{1}\left(\lambda_{j}\right), I_{2}-G_{2}\left(\lambda_{j}\right) h_{2}\left(\lambda_{j}\right), \ldots,\right. \\
& \left.I_{i}-G_{i}\left(\lambda_{j}\right) h_{i}\left(\lambda_{j}\right), \ldots, I_{m}-G_{m}\left(\lambda_{j}\right) h_{m}\left(\lambda_{j}\right)\right]\left.\right|_{P=P}(r) \\
& , j=1,2, \ldots, l
\end{aligned}
$$

Using the following identity of determinants

$$
\begin{aligned}
\operatorname{det}\left[A_{1}+B_{1}, A_{2}+B_{2}, \ldots, A_{i}+B_{i}, \ldots, A_{m}+B_{m}\right] \\
=\operatorname{det}\left[A_{1}+B_{1}, A_{2}+B_{2}, \ldots, A_{i}, \ldots, A_{m}+B_{m}\right]+ \\
\quad \operatorname{det}\left[A_{1}+B_{1}, A_{2}+B_{2}, \ldots, B_{i}, \ldots, A_{m}+B_{m}\right]
\end{aligned}
$$

, eqn. (20) becomes

$$
\begin{aligned}
\Delta d_{j}^{(r)}= & \operatorname{det}\left[I_{1}-G_{1}\left(\lambda_{j}\right) h_{1}\left(\lambda_{j}\right), I_{2}-G_{2}\left(\lambda_{j}\right) h_{2}\left(\lambda_{j}\right), \ldots, I_{i}, \ldots,\right. \\
& \left.I_{m}-G_{m}\left(\lambda_{j}\right) h_{m}\left(\lambda_{j}\right)\right] \mid P=P^{(r)} \\
& -h_{i}\left(\lambda_{j}\right) \operatorname{det}\left[I_{1}-G_{1}\left(\lambda_{j}\right) h_{1}\left(\lambda_{j}\right), I_{2}-G_{2}\left(\lambda_{j}\right) h_{2}\left(\lambda_{j}\right), \ldots,\right. \\
& \left.G_{i}\left(\lambda_{j}\right) \ldots, I_{m}-G_{m}\left(\lambda_{j}\right) h_{m}\left(\lambda_{j}\right)\right]\left.\right|_{p=P^{(r)}}
\end{aligned}
$$

Then, the partial derivative of $\Delta d_{j}{ }^{(r)}$ with respect to $p_{i}$ is given by

$$
\begin{gathered}
\frac{\partial \Delta d_{j}^{(r)}}{\partial p_{i}}=-\frac{\partial h_{i}\left(\lambda_{j}\right)}{\partial p_{i}} \quad \operatorname{det}\left[I_{1}-G_{1}\left(\lambda_{j}\right) h_{1}\left(\lambda_{j}\right), I_{2}-G_{2}\left(\lambda_{j}\right) h_{2}\left(\lambda_{j}\right), \ldots,\right. \\
\left.G_{i}\left(\lambda_{j}\right), \ldots, I_{m}-G_{m}\left(\lambda_{j}\right) h_{m}\left(\lambda_{j}\right)\right)\left.\right|_{P=P^{(r)}}
\end{gathered}
$$

and

$$
\begin{aligned}
& \frac{\partial \operatorname{Real}\left(\Delta d_{j}^{(r)}\right)}{\partial p_{j}}=-\operatorname{Real}\left\{\frac { \partial h _ { j } ( \lambda _ { j } ) } { \partial p _ { j } } \operatorname { d e t } \left[I_{1}-G_{1}\left(\lambda_{j}\right) h_{1}\left(\lambda_{j}\right),\right.\right. \\
& I_{2}-G_{2}\left(\lambda_{j}\right) h_{2}\left(\lambda_{j}\right), \ldots, G_{j}\left(\lambda_{j}\right), \ldots \\
& \left.\left.I_{m}-G_{m}\left(\lambda_{j}\right) h_{m}\left(\lambda_{j}\right)\right]\right\}\left.\right|_{P=P^{(r)}}
\end{aligned}
$$

$$
\begin{aligned}
\frac{\partial I_{\operatorname{mag}}\left(\Delta d_{j}^{(r)}\right)}{\partial p_{i}}=- & I_{\text {mag }}\left\{\frac { \partial h _ { i } ( \lambda _ { j } ) } { \partial p _ { i } } \operatorname { d e t } \left[I_{1}-G_{1}\left(\lambda_{j}\right) h_{1}\left(\lambda_{j}\right),\right.\right. \\
& I_{2}-G_{2}\left(\lambda_{j}\right) h_{2}\left(\lambda_{j}\right), \ldots, G_{i}\left(\lambda_{j}\right), \ldots, \\
& \left.\left.I_{m}-G_{m}\left(\lambda_{j}\right) h_{m}\left(\lambda_{j}\right)\right]\right\}\left.\right|_{P=P^{(r)}}
\end{aligned}
$$


for complex conjugate eigenvalues $\lambda_{j}$. Using eqns. (23) and (24), we obtain the determinant mismatch equation
$\Delta \mathrm{D}^{(\mathrm{r})}=\mathrm{J}^{(\mathrm{r})} \Delta \mathrm{P}^{(\mathrm{r})}$

Eqn. (25) can be expressed in explicit form

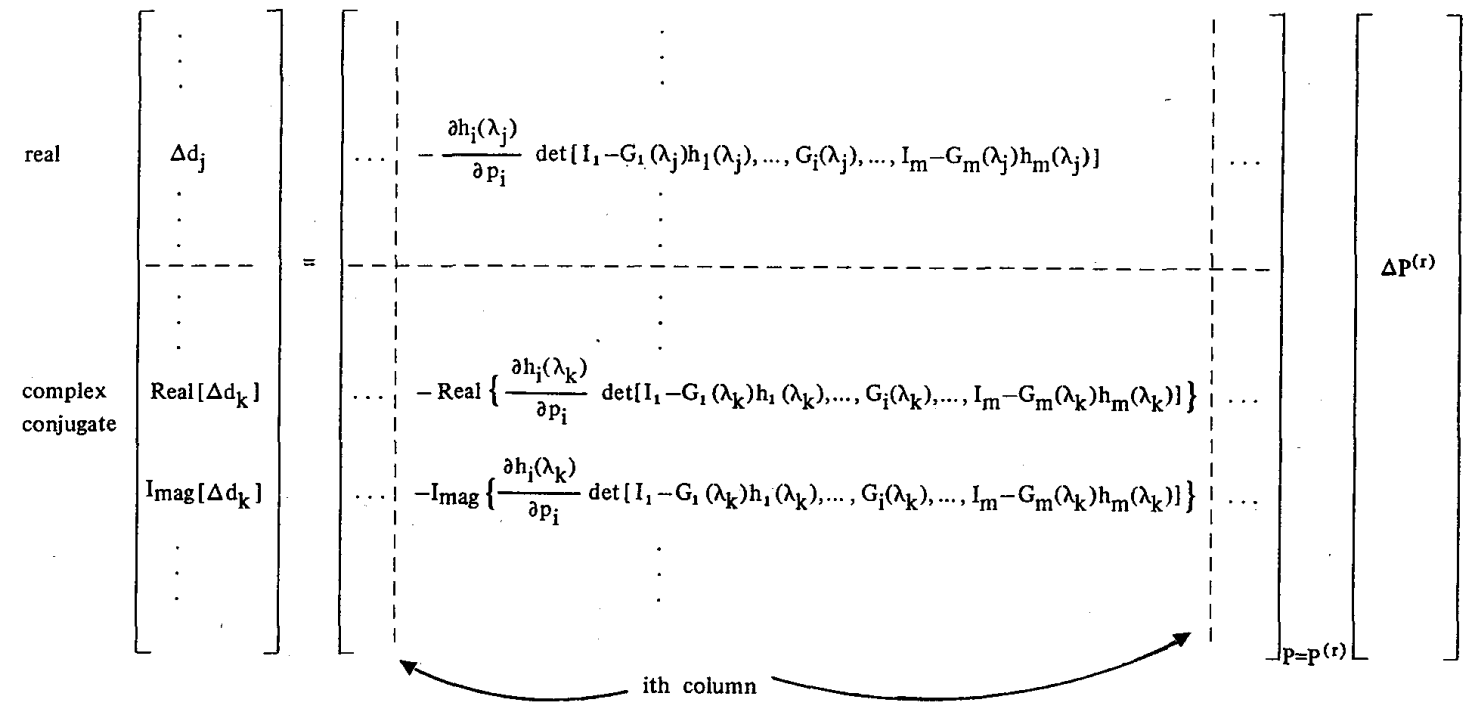

Finally, eqn. (19) follows directly from eqn. (25).

\section{EXAMPLE}

The system considered is the 1984 Taiwan power system of which the single-line diagram is shown in Fig. 1 . There are 14 generating units geographically located at three different areas on the island of Taiwan with a distance of $400 \mathrm{Km}$ from the north to the south. The three areas are designated as $\mathrm{N}$ (the northern area), $C$ (the central area), and $S$ (the southern area), respectively. The bus number, bus name, real and reactive power generation, voltage magnitude and angle for each generator bus are listed in Table 1 . Detailed descriptions of the generator and exciter constants for this system can be found in [17]:

In the design of power system stabilizers for multimachine power systems, the original Heffron-Phillips-deMello-Concordia generator model [5] must be first generalized to take the dynamical interactions between machines into account. The result is a multimachine model as shown in Fig. 2 in which the machine interactions are represented by the constants $K_{1 i j}, K_{2} \mathbf{j j}, \ldots, K_{6 i j}$. The state equations required for the computation of participation factors and determination of stabilizer constants can then be derived directly
Table 1. Summary of generator bus data for Taiwan power system

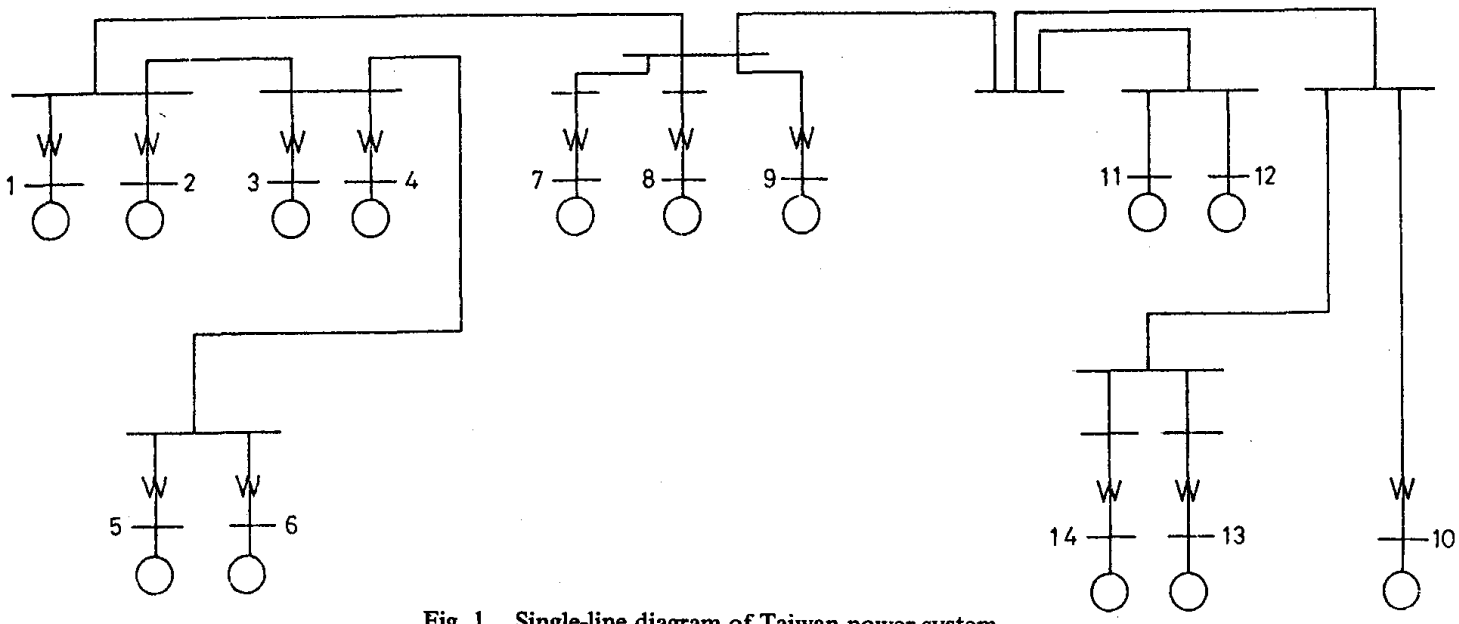

Fig. 1 Single-line diagram of Taiwan power system 


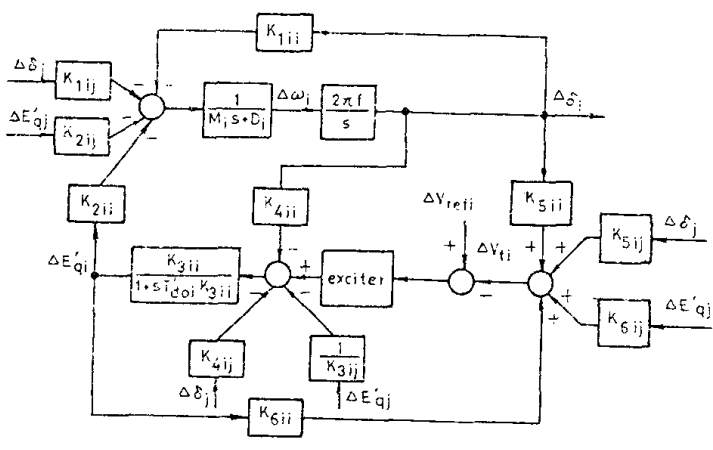

Fig. 2 Block diagram for multimachine power system

from this model. The computed participation factors for the 13 electromechanical modes are given in Table 2 . The data which is needed for the computation of the constants $\mathrm{K}_{1}-\mathrm{K}_{6}$ and system state equations leading to the data in Table 2 is the system information for dynamic stability analysis including the machine and exciter constants, power flow data for the study system, and network data

It should be noticed that only the participation factors for $\Delta \delta$ and
$\Delta \omega$ of each generators deserve special consideration since the mechanical modes describe the characteristics of the torque angle deviations and angular speed deviations.

From the electromechanical mode eigenvalues in Table 2 , it is decided to install four stabilizers in order to improve the dampings of the four mechanical modes with worst damping: $0.05 \pm \mathrm{j} 6.070$, $-0.164 \pm \mathrm{j} 10.968,-0.126 \pm \mathrm{j} 11.688$, and $-0.158 \pm \mathrm{j} 9.065$. The blocked entries in Table 2 indicate that generators \#7, 8, 9, and 12, which have the greatest participation factors for these four modes with real parts greater than -0.2 , are the optimum stabilizer locations. So far, the most widely employed stabilizer in power systems is the lead-lag stabilizer whose transfer function is given by

$$
h_{i}(s)=\frac{T_{w} S}{1+s T_{w}} \cdot K_{i} \cdot \frac{\left(1+s T_{1 i}\right)^{2}}{\left(1+s T_{2}\right)^{2}}
$$

where $T_{W}$ is the washout time constant which is usually chosen to be $1 \mathrm{~s}$, and $T_{2}$ is often set to be $0.05 \mathrm{~s} \mathrm{[6].} \mathrm{This} \mathrm{leaves} \mathrm{the} \mathrm{other}$ two stabilizer parameters $K_{i}$ and $T_{1 i}$ to be determined. Using four pairs of prespecified eigenvalues, these stabilizer parameters can be calculated by using the algorithm described in the previous section.

The computed values of stabilizer parameters are given in Table 3 and the eigenvalues of the closed-loop system equipped with these stabilizers are listed in Table 4 . It can be observed that the four pairs of prespecified eigenvalues have been exactly assigned after the installation of the designed stabilizers.

Table 2. Participation factors for the generators in Taiwan power system

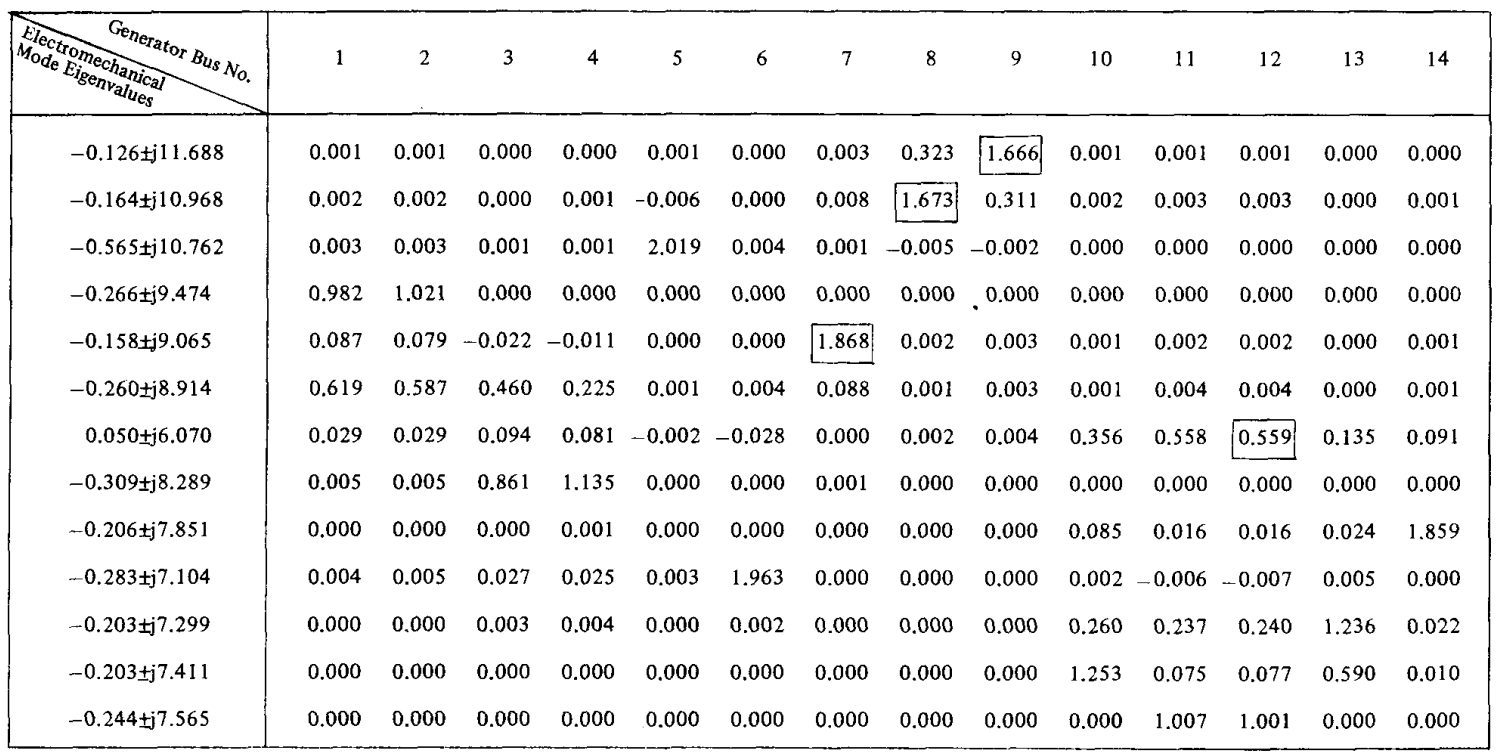

Table 3. The Computed Stabilizer Parameter Values

\begin{tabular}{|c|c|c|c|}
\hline $\begin{array}{l}\text { installed } \\
\text { generator } \\
\text { number }\end{array}$ & parameter & Case I & Case II \\
\hline$\# 7$ & $\mathrm{~K}$ & -2.51727 & -9.41134 \\
& $\mathrm{~T}_{1}$ & 0.05995 & 0.01227 \\
\hline$\# 8$ & $\mathrm{~K}$ & -1.53428 & -4.22871 \\
& $\mathrm{~T}_{1}$ & 0.05536 & 0.01938 \\
\hline$\# 9$ & $\mathrm{~K}$ & -8.10556 & -15.3055 \\
& $\mathrm{~T}_{1}$ & 0.04347 & 0.02467 \\
\hline$\# 12$ & $\mathrm{~K}$ & -39.76329 & -48.07926 \\
& $\mathrm{~T}_{1}$ & 0.00846 & 0.01125 \\
\hline
\end{tabular}

Table 4. The Closed-loop System Eigenvalues

\begin{tabular}{|c|c|}
\hline Case I & Case II \\
\hline-0.200 」j $11.600^{*}$ & $-0.300 \pm \mathrm{j} 11.600^{*}$ \\
\hline$-0.200 \pm j 10.900^{*}$ & $-0.300 \pm \mathrm{j} 10.900^{*}$ \\
\hline$-0.200 \pm j 9.000^{*}$ & $-0.300 \pm j 9.000^{*}$ \\
\hline$-0.200 \pm j 6.000^{*}$ & $-0.300 \pm j 6.000^{*}$ \\
\hline$-0.565 \pm j 10.762$ & $-0.564 \pm j 10.762$ \\
\hline$-0.266 \pm j 9.474$ & $-0.266 \pm j 9.474$ \\
\hline$-0.235 \doteq j 8.899$ & $-0.326 \pm j 8.843$ \\
\hline$-0.309 \pm j 8.289$ & $-0.310 \pm j 8.289$ \\
\hline$-0.207 \pm j 7.848$ & $-0.207 \pm j 7.848$ \\
\hline$-0.675 \pm j 7.097$ & $-0.732 \pm j 6.919$ \\
\hline$-0.287 \pm j 7.097$ & $-0.289 \pm j 7.098$ \\
\hline$-0.230 \pm j 7.347$ & $-0.226+j 7.348$ \\
\hline$-0.216 \pm j 7.422$ & $-0.215 \pm j 7.423$ \\
\hline
\end{tabular}

* denote the exact assignment of eigenvalues 


\section{CONCLUSIONS}

A new and efficient approach for the design of decentralized power system stabilizers for large-scale power systems has been presented. Identification of optimum stabilizer has been also examined. The effectiveness of the proposed method is demonstrated by an example of stabilizer design for a practical power system. It is found that the eigenvalues of the system can be exactly assigned to certain desirable prespecified locations by using the designed decentralized stabilizers.

The method is efficient that for the multimachine power system considered in this paper the required CPU time on the VAX-11/780 computer is only about $5 \mathrm{sec}$. As for the three-machine to infinitebus system which was considered in a previous paper [18], the CPU time elapsed on the same computer is $1.2 \mathrm{sec}$ or so. Obviously, the computational effort would increase if the number of generators is increased.

It should aiso be noticed that this paper merely gives a general algorithm for computing PSS parameters. No matter how efficient it is, adequate knowledge and experiences are necessary for selecting which oscillation modes to be controlled and time-domain simulation taking the nonlinearities of the system into account has to be performed before on-line installation.

\section{REFERENCES}

[1] Y.Y. Hsu, S.W. Shyue and C.C. Su, "Low frequency oscillations in longitudinal power systems: Experience with dynamic stability of Taiwan power system", IEEE Trans. PWRS, Vol. 2, pp. 92-100, 1987.

[2] C. Barbier, E. Ferrari and K. E. Johansson, "Questionnaire on electromechanical oscillation damping in power systems: Report on answers", ELECTRA, Vol. 64, pp. 59-90, 1979.

[3] F. R. Schleif and J.H. White, "Damping for the NorthwestSouthwest tieline oscillation-an analog study", IEEE Trans. PAS, Vol. 85, pp. 1239-1247, 1966.

[4] P.A. Rusche, D.L. Hackett, D.H. Baker, G.E. Gareis and P.C. Krause, "Investigation of the dynamic oscillations of the Ludington pumped storage plant", IEEE Trans. PAS, Vol. 95 , pp. 1854-1862, 1976.

[5] F.P. deMello and C. Concordia, "Concepts of synchronous machine stability as affected by excitation control", IEEE Trans. PAS, Vol. 88, pp. 316-329, 1969.
[6] E. V. Larsen and D.A. Swann, "Applying power system stabilizers", IEEE Trans. PAS, Vol. 100, pp. 3017-3046, 1981.

[7] P.M. Anderson and A. A. Fouad, Power System Control and Stability, Iowa State University Press, Ames, Iowa, 1977.

[8] H.A.M. Moussa and Y.N. Yu, "Optimal power system stabilization through excitation and/or governor control", IEEE Trans. PAS, Vol. 91, pp. 1166-1174, 1972.

[9] W.C. Chan and Y.Y. Hsu, "An optimal variable structure stabilizer for power system stabilization", IEEE Trans. PAS, Vol. 102, pp. 1738-1 746, 1983.

[10] Y.Y. Hsu and C.Y. Hsu, "Design of a proportional-integral power system stabilizer”, IEEE Trans. PWRS, Vol. 1, No. 2, pp. 46-53, May 1986.

[11] F.P. deMello, P.J. Nolan, T.F. Laskowski and J.M. Undrill, "Coordinated application of stabilizers in multimachine power systems", IEEE Trans. PAS, Vol. 100, pp. 2329-2333, 1981 .

[12] G.C. Verghese, I.J. Perez-Arriaga, F.C. Schweppe, and K.W.K. Tsai, Selective Modal Analysis in Power Systems, EPRI Report, EL-2830, 1983.

[13] I. J. Perez-Arriaga, G.C. Verghese and F.C. Schweppe, "Selective modal analysis with applications to electric power systems", IEEE Trans, PAS, Vol. 101, pp. 3117-3134, 1982.

[14] Y.Y. Hsu and C. L. Chen, "Identification of optimum location for stabilizer applications using participation factors", to appear in Proc. IEE, Pt. C, 1987.

[15] H. Seraji, "Pole assignment using dynamic compensators with prespecified poles", Int. J. Control. Vol. 22, pp. 271279,1975 .

[16] H. Kimura, "Pole assignment by gain output feedback", IEEE Trans. AC, Vol. 20, pp. 509-516, 1975

[17] Y.Y. Hsu, Frequency Domain Analysis of Power System Dynamic Stability-Phase I, Research Report of Taiwan Power Company, 1985.

[18] C.L. Chen and Y.Y. Hsu, "Coordinated synthesis of multimachine power system stabilizer using an efficient decentralized modal control algorithm", Paper No. 86 SM 3214, presented at IEEE/PES 1986 Summer Meeting, Mexico City, Mexico.

\section{Discussion}

Ali Feliachi (West Virginia University, Morgantown, WV): The authors are to be commended for their work on the design of power system stabilizers. This paper reports on the identification of the location of stabilizers [1] and the determination of their parameters.

The discusser does not agree with the approach taken to determine the location of the stabilizers. The authors use the open-loop matrix to compute the participation factors; however, these quantities will change with the implementation of the stabilizers since the eigenvectors of the closed-loop system will be different in general. What is the authors' experience, if any, with this problem?

The design algorithm is an iterative technique to determine the controller parameters. Since the controller is an output decentralized scheme, will the authors comment on the following questions:

1) Is the scheme always feasible? If not, what are the necessary conditions [2]?

2) The proposed method is iterative. What is the authors' experience with convergence?

3) Lim and Elangovan [3] have proposed a noniterative approach to determine the parameters of power system stabilizers. Have the authors compared their work to this approach?

4) Could the authors give the values of the open-loop eigenvalues and comment on eigenvalue drift?

\section{References}

[1] Y. Y. Hsu and C. L. Chen, "Identification of optimum location for stabilizer applications using participation factors," IEEE Proc., vol. 134, pt. C, no. 3, pp. 238-244, May 1987.
[2] A. Feliachi, "Optimal decentralized load frequency control," IEEE Trans. Power Syst., vol. PWRS-2, no. 2, pp. 379-386, May 1987.

[3] C. M. Lim and S. Elangovan, "A new stabilizer design technique for multimachine power systems," IEEE Trans. Power App. Syst., vol. PAS-104, pp. 1738-1746, 1985.

Manuscript received August 3, 1987.

Chern-Lin Chen and Yuan-Yih Hsu: The authors would like to thank the discusser for his interest in the paper. We would like to answer the questions raised by Dr. Feliachi as follows.

1) The use of the eigenvectors of the open-loop system as a basis for the identification of stabilizer locations is more reasonable than the use of closed-loop system eigenvectors. This is due to the fact that the locations of the stabilizers must be determined before the tuning of stabilizer parameters. Thus the study system is still open-loop while the choice of stabilizer locations is made.

2) The presented scheme may not always be feasible because the convergence of the Newton-Raphson method cannot be guaranteed. However, a proper set of initial guesses for stabilizer parameters will lead to good convergent characteristic. In view of the feasibility of direct computation for a single PSS and the weak interactions among the generating units at different plants, the set of parameters determined sequentially by shifting the electromechanical mode associated with a particular generator on which a PSS is installed can be used as initial guesses. Excellent convergent characteristic has been observed for the suggested initial guess [A].

3) The approach presented by Lim and Elangovan used the fixed-point numerical method to find the solutions. It is iterative in nature. Their achievement is praiseworthy and has demonstrated some advantages 
over previous works. However, the matrix-reduction technique, which is the kernel of the whole solution procedure, can only be applied to special cases where the PSS input is one of the system state variables [B].

4) The open-loop eigenvalues are listed in the first column of Table 2 . On comparing the results in Table 2 and Table 4 , it is found that no significant drifts in the unassigned eigenvalues have been observed except for a complex pair: the mode $-0.244 \pm j 7.565$ shifts to -0.675 $\pm j 7.097$ in case I and to $-0.732 \pm j 6.919$ in case II. This can be explained by the participation factors of generator \#12. Since generator \#12, which is equipped with a well-tuned PSS, participates significantly in modes $0.05 \pm 6.070$ and $-0.244 \pm 7.565$, a strong control force goes to the latter

\section{References}

[A] C. L. Chen, "Decentralized modal control algorithm and its application to power system stabilizer design," Ph.D. dissertation, National Taiwan Univ., Taipei, Taiwan, 1987.

[B] C. L. Chen and Y. Y. Hsu, "Design of decentralized stabilizers in multimachine power systems," Proc. IEE, vol. 134, pt. C, no. 4, pp. 289-290, 1987.

Manuscript received September 1, 1987. 